\title{
Blogging Astrophysics, Shaping the Self. Content-mediated Identity Negotiation and Peer Group Adjustment in a Sample of Astrophysicists' Blogs
}

\author{
Monica Marra ${ }^{1}$ \\ ${ }^{1}$ Istituto Nazionale di Astrofisica. Osservatorio di Astrofisica e Scienza dello Spazio, Bologna
}

\begin{abstract}
Research blogging has received a rather good amount of attention from the scholarly literature, but not in the domain of astrophysics. In the present paper, three active astrophysicists' blogs have been chosen from a previously retrieved wider corpus and analyzed against the pivotal theory of identity shaping in an online setting. The study, which is essentially mixed-methods, has built on Susan Herring's definition of computer-mediated conversation and focusses on content analysis as well as on content-based interaction (comments and replies per subject). Special care was taken on ensuring bloggers' and commenters' anonimity, in compliance with the British Psychological Society Ethics Guidelines. These blogs' conversational capacity has emerged and the hypothesis of some degree of professional identity negotiation results to be confirmed, with implications on the invisible colleges. The context is that of an interdisciplinary, provisional junction between ground-based linguistic fieldwork in a 2.0 online setting and the search for appropriate theoretical frameworks about unconscious or semi-conscious aims of communication in a scholarly environment.
\end{abstract}

Keywords: blogs, research blogs, identity shaping, astrophysics, 2.0 communication, computer-mediated communication, scholarly communication, invisible colleges

\section{Literature review}

Blogs (or, in the initial denomination, weblogs) have been defined as a specific genre, "situated at an intermediate point between standard Web pages and asynchronous computerBlogging astrophysics, shaping the self 
mediated communication" (Herring, 2004, p.10). As research objects, they appear to have encountered two major waves of popularity: the first one around the apex of their success (e.g.: Blood, 2002; Herring, 2004; De Moor \& Efimova, 2004; Halavais, 2005; Efimova \& De Moor, 2005; Herring, 2005) and a second, consistent round of studies circa between 2009 and 2014 (e.g. Kjellberg, 2009; Kirkup, 2010; Shema et al., 2012; Siles, 2012; Kjellberg, 2014; Mahrt \& Puschmann, 2014). A satisfactory historical account of the phenomenon is still in process of achievement, with notable advances in recent years (e.g. Siles, 2018).

Scholars who have investigated the phenomenon have employed a variety of methodologies, as noted by Puschmann, 2013 (see also Shema et al., 2012, in more general terms). The most convincing studies have consisted of multi-level and/or multi-type inquiries (e.g. Herring, 2004; Kjellberg, 2009; Kirkup, 2010; Shema et al., 2012; Kjellberg, 2014; Mahrt \& Puschmann, 2014), whereas approaches strictly aimed at blogs' formal characteristics have seemed to "miss something of their essence" (Ewins, 2005, p.370).

The present study is dedicated to a specific subset of blogs, namely scholarly blogs, in the particular area of astrophysics (the sampling criteria are described infra), believing that the results can be extended to a wider disciplinary area including, at least, the physics domain. To our knowledge, active astrophysicists' blogs have received a small amount of specific attention hitherto, with the exception of Ritson's paper about blogs' trackbacks with ArXiv (Ritson, 2016). The present study chooses a synchronic approach, focussing upon a stimulating feature which has been observed both in blogs in general and in researchers' blogs in particular, i.e. bloggers' online identity shaping as implemented through their blogging activity.

The affordance of the internet technologies in general for identity building can be considered a classic stand, which the literature has acknowledged timely (e.g. Turkle, 1994; Cerulo, 1997; Turkle, 1999). Blogs have been recognized to share this affordance. Efimova \& Hendrick have maintained that "What makes weblogs different is [...] the personalities behind them. Weblogs are increasingly becoming the online identities of their authors" $(2005$, p.2). In the insightful paper by Ewins, a blogging researcher himself, "weblogs [...] afford opportunities for identity construction and reconfiguration" - up to the point that they "can end up changing their authors' sense of identity in ways they may not expect" (2005, p.368). While introducing the book Uses of blogs, Bruns \& Jacobs highlight that "the negotiation of identity online can be realized through the instrument of blogging" (2006, p.4). Kirkup, another blogging academic, claims that "blogging is [...] a genre 
through which academics [also] perform their scholarly identity" (2010, p.83); Yus (following Boyd, 2006 as well as Efimova et al., 2005) hypothesizes that "by updating their blogs, the bloggers shape, strengthen and develop their identities." (2011, p.97). Siles' thoughtful contribution about blogs in general is all centered around "the formation of the identities of the blogger" as "an ongoing process" (2012, p.419). Much the same has been maintained in more occasional claims both by scholars (Kjellberg 2009 p.23) and by some of the astrophysicists in our sample during their blogging activity, as encountered along the making of the present research.

At the basis of most of the literature supporting this stand lies Foucault's technology of the self, which has been adopted both alone or combined with other theories, and accessed either directly or mediated through different scholars' work (Ewins 2005, Kirkup 2010, Mewburn \& Thomson 2017; also, Siles 2012 about blogs in general).

Central to our perspective is a feature that enables the blogging activity to unfold this special kind of operativity, i.e. its conversational affordance as supplemental to its mere, and mainstream, communication capacity.

Blogs' very nature as a conversational venue has been convincingly supported, both as a pivotal feature (DeMoor \& Efimova 2004; Halavais, 2005; Herring et al., 2005; Efimova \& De Moor, 2005; Efimova, 2009; Kjellberg, 2009; Herring, 2010a) and in looser claims of its relevance (e.g. Ewins, 2005; Rettberg, 2008, for whom "blogs are remarkable for combining aspects of both dialogue and dissemination", p. 6; Yus, 2011). An explicit rejection of this stand from a linguistic (jacobsonian) perspective is the dedicated study by Peterson, who questions blogs' conversational nature by highlighting "the ambiguity and doubling of both addresser and addressee" (Peterson, 2011, p.6). This thesis, though, has been convincingly reframed by Herring ("although Peterson does not address this explicity [...] blogs that receive responses (e.g. in comments posted to blog entries) can be considered conversations albeit asymmetrical ones in which the blog author controls the floor"; Herring, 2010, p.4).

In fact, in the literature examined, the acknowledgement of identity building capacities to blogs has been coupled with their analysis as computer-mediated conversations in a very limited number of cases. The enlightening papers by Ewins and by Mewburn \& Thomson are based upon auto-ethnographic observations and on survey-grounded data respectively. Kirkup's findings rely on interviews to academic bloggers. Siles' culture-savvy paper is substantially a deep qualitative overview of a sample of early bloggers' beliefs, plus literature. Three of the authors examined have 
focussed more extensively upon language: Herring, Efimova - both of which with colleagues - , and Kjellberg. In her latest paper on the subject, self-defined as "an ethnographically inspired study" (Kjellberg 2014 p.48), the latter inquires research blogs' "aim, form, content and context" building on "an analytical framework based on genre theory (ibid., p.36)". The paragraph about content, an element that will be central for the present research, starts from the sharable premise that "[...] the topics addressed are an important part of what constitutes a genre [...] content can be the selection principle for a study of [research] blogs [...]" (p.58). Context, as well, is examined strarting from sound remarks ("The context of the blog has to do with the practices in which it takes part and the conversations that take place in and around it.”, p.61). For both sections the approach is qualitative; unfortunately, nothing is said about how the bloggers' identities are affected by the peculiar mixtion of "public and [...] private (p.61)" which characterises blogs. In fact, this author seems to be more interested in clarifying how research blogs differ from more established research communication venues and, in fact, blogging as a technology of the self appears to be an isolated remark in her work.

The work by Herring and colleagues on one side, and Efimova and colleagues on the other side, have subtly intertwined around 2004-2005 about the relative weight of external links as blogs' constitutive factors and as primary marks of conversationality. Efimova and colleague(s) have been in favour of this hypothesis, thus focussing chiefly on communication dynamics (e.g.: "“"([...] we will not address the contents of the conversation. Instead, we focus on examining the distributed nature of the conversation process, one of the key aspects of blog-mediated conversations." (DeMoor\&Efimova 2004 p. 200; see also Efimova\&DeMoor 2005 p.2). Herring's work is of great importance for the present research. We can't follow the evolution of her thought, which, e.g., initially opposed to giving links a prominent weight in web and blog analysis (Herring et al., 2004; Herring et al., 2005a) and then cleverly incorporated them in her proposal of Web Content Analysis (Herring, 2010a). Even more than in her valuable studies about blogs (chiefly: Herring et al. 2004; Herring et al., 2005b), the fruifulness of her contribution to blog analysis seems to lie in this latter theorization, where she substantially claims for more flexibility in content analysis' principles and methodology when applied to web content, while calling for the preservation of rigour.

The aim of the present research is giving insight into the shaping of the self in a small sample of research blogs, believing and arguably demonstrating that they are conversational venues. To this aim the analysis will be focused on the subjects of posts and on the countable interactions represented by readers' comments as well as by bloggers' replies. This kind of approach is basically 
rooted in linguistics, but it hasn't the ambition to meet all the principles and standards envisioned by Herring for her Web Content Analysis theory. Rather, it locates itself in a substantially empirical, interdisciplinary research area that is connected with ethnography as well as with social network analysis. Nevertheless, the methodology adopted does encompass some of Herring's prescriptions (Herring 2010a p. 11), such as the analysis of themes and textual exchanges, the refusal of random sampling and the highlighting of quantitative outcomes.

As a starting principle, I will build on Herring's self-defined "broad definition" (Herring, 2010b, p.4) of computer-mediated conversation, be it synchronous or asynchronous, as "any exchange of messages between two or more participants, where the messages that follow bear at least minimal relevance to those that preceded or are otherwise intended as responses" (ibid.).

This study also resonates with two claims by Efimova \& DeMoor (2005): "we define a weblog conversation as a series of interrelated (interlinked) weblog posts and comments on a specific topic (p. 1; emphasis added) and "the conversation model needs to be extended: more attention should be paid to goals and topic dynamics." (p.9). The aim is grasping blogs' relevance for the negotiation of their authors' selves through computer-mediated conversation, in relation to their audience.

\section{Method}

The analysis has been conducted on a sample of three blogs written by astrophysicists, out of a much wider corpus of blogs by physicists and astrophysicists which I have retrieved for future insights. The main criteria for identifying the sample have been: a) the presence of a sufficiently ample interaction with readers; b) the avoidance of both the typology of outreach blogs and that of monothematic blogs, intended as blogs entirely dedicated either to science alone or to scholars' personal interests other than science - reasons for which will be patent below. The three blogs which have been chosen have been created around the same years, are all written in English and are the creations of three active, tenured researchers. They all exhibit a multi-topic feature, placing side by side posts about science with a rather broad set of different subjects ranging from cultural and social topics to humour, including accounts of personal or academic life experiences. Out of privacy concerns, and in compliance with the Ethics Guidelines for Internet-mediated Research by the British Psychological Society (2017), these blogs' titles and urls, as well as authors' and commenters' names, nicknames and any other data potentially leading to identification of the 
concerned people won't be disclosed, being substituted by conventional labels. Accordingly, we will find blog A, blog B, blog C; Blogger A, Blogger B, Blogger C. Also, textual citations will be avoided and the data will be provided in numerical forms.

The total amount of data analyzed in the present study consists of 1763 posts, 2344 comments and 863 bloggers' replies in the three blogs, which were investigated for a maximum duration of four years (varying according to the considered features and/or for single blogs, which will be better detailed below). Given a common inclination by the three bloggers to put in place non-obvious semantic strategies when conveying the meaning of posts (e.g.: relation between titles and contents of posts), and also a common tendency to digress, the subject coding of all posts and the examination of comments were conducted manually, with a relevant time investment. This has reasonably led to data of a reliable semantic quality. A particular treatment had to be reserved to blog $\mathrm{C}$, being its author a frequent poster with an average of 54.66 posts per month in the first three months - remaining sizeable also in the following months - and with high amounts of comments. In the case of blog $\mathrm{C}$, the content analysis was conducted on the blog's first three months of life (164 posts), with percentages being taken as an extrapolation for the whole first year.

The data have been investigated according to four research questions. The first one revolves around bloggers' choice of topics; the second and third ones call forth bloggers-readers interaction, as follows:

RQ1) How big is the role of science as a topic of choice in these astrophysicists' blogging practice?

RQ2) How attractive are the different topics for these blogs' readers in general and for peers in particular, as witnessed by amounts of comments?

RQ3) How does the response from readers to the different topics affect subsequent bloggers' practice?

The answers to RQ1, RQ2, RQ3 will be leveraged for the coming to light of conversational dynamics finalized to the shaping of online selves by the examined bloggers. The final research question is:

RQ4) What can we infer from the content dynamics emerging from RQ1, RQ2, RQ3, in relation to these blogging astrophysicists' shaping of their online selves? 


\section{Bloggers' choice of topics}

Posts in the three blogs were coded according to six content categories - comparable for more than $50 \%$ to the seven "themes" in Kjellberg (2009) -, i.e.: Pure Science (scientific findings/comments on relevant papers/significant science news); Science Politics; Personal or biographic notes; Culture/Society/Politics; Academic Life; Other (including humour).

Table 1 below summerises the results for the first year, based upon 508 total posts (effective year for blogs A and B with a total of 344 posts; 164 posts for the first three months in blog C, being considered as an extrapolated year's values).

\section{Table 1}

Distribution of posts by subject during the first 12 months (blogs $A, B, C$ )

Science, Science Personal Culture/Society Acad. Other Total

Pure (\%) Politics $\quad$ bio (\%) $/$ Politics $(\%) \quad$ Life $(\%) \quad(\%) \quad(\%)$

$(\%)$

\begin{tabular}{lccccccc}
\hline Blog A & 14.285 & 9.398 & 12.406 & 31.578 & 12.406 & 19.924 & 99.99 \\
Blog B & 7.692 & 12.820 & 8.974 & 26.923 & 14.102 & 29.487 & 99.99 \\
Blog C & 14.024 & 1.829 & 14.024 & 29.268 & 20.731 & 20.121 & 99.99 \\
\hline $\begin{array}{l}\text { Maximum } \\
\text { interval }\end{array}$ & 6.593 & 10.991 & 5.050 & 4.655 & 8.325 & 9.563 & $/$
\end{tabular}

Three elements emerge: a) for none of the bloggers in our sample, pure science is the elective topic for blogging. This topic's percentages in the considered bloggers' first year of activity rank between 3rd (blog A), 4th (blog C) and 6th or last position (blog B). B) Interestingly, the ranges in topic percentages in the three considered blogs are narrow. With the exclusion of Science Politics, which seems to be outside the interests of Blogger $\mathrm{C}$, differences in topic percentages among the three blogs are always lower than $10 \%$ (as low as $4.655 \%$ for Culture/Society/Politics). Thus, there seems to exist a sort of - undoubtedly unintended - "common recipe" for composing these blogs' overall pictures in their first year of life, which is easlily inferable from Table 1. The first topic of choice both for Blogger A and for Blogger C is by far Culture/Society/Politics, which ranks second for Blogger B. 
The data in Table 1 result to be rather robust along time in our context as proved by the multi-year analysis conducted on blogs A and B (Table 2 below). For blog A, 4 years' posts have been analyzed (1448 posts) and three years' posts have for blog B (151 posts; years 1,3,4). In blog $\mathrm{B}$, the second year's posts had in fact been processed but had later to be excluded from the analysis, having been too heavily invested by a disciplinary controversy which altered the values in the subject categories to an excessive extent. The globally low intervals among highest and lowest percentages in the six considered subject categories, along the period considered, prove a perceivable stability in these three blogs' subject composition along time (see Table 2 below). Culture/Society/Politics and Other get a sudden peak for blog B in one of the years considered, which partly but not substantially conditions the overall picture.

\section{Table 2}

Maximum interval among yearly percentages per subject, per blog (blogs A, B) along 4/3 years

\begin{tabular}{lcccccc} 
& $\begin{array}{c}\text { Science, } \\
\text { Pure }\end{array}$ & $\begin{array}{c}\text { Science } \\
\text { Politics }\end{array}$ & $\begin{array}{c}\text { Personal / } \\
\text { bio }\end{array}$ & $\begin{array}{c}\text { Culture/Society } \\
\text { / Politics }\end{array}$ & $\begin{array}{c}\text { Academic } \\
\text { Life }\end{array}$ & Other \\
& & & & & & \\
\hline Blog A (4 yrs) & 4.840 & 5.638 & 6.326 & 4.800 & 5.340 & 5.716 \\
Blog B (3 yrs) & 7.540 & 7.180 & 11.110 & 30.000 & 8.970 & 15.207 \\
\hline
\end{tabular}

Substantially, the average figure of the multi-year content analysis for blogs A and B, and for the extrapolated year in blog $\mathrm{C}$, is the following:

\section{Table 3}

More extended content analysis (blog A: 4 yrs. average; blog B: 3 yrs. av.; blog C: 1 yr. (extr.) av.)

Science, Science Personal Culture/Soc./ Acad. Other

Pure (\%) Politics (\%) / bio (\%) $\quad$ Politics (\%) $\quad$ Life (\%) $\quad(\%)$

\begin{tabular}{lcccccc}
\hline Blog A, 4 yrs. average & 14.716 & 6.982 & 9.557 & 30.745 & 14.537 & 23.441 \\
Blog B, 3 yrs. average & 7.460 & 15.700 & 6.690 & 32.310 & 13.610 & 24.220 \\
Blog C, 1 yr. (extr.) av. & 14.024 & 1.829 & 14.024 & 29.268 & 20.731 & 20.121 \\
\hline
\end{tabular}




\section{Bloggers-readers interaction: readers' comments and bloggers' replies}

Examining the readers' response to the three blogs considered introduces into the territory of interactions between bloggers and their readers. On the basis of Herring's definition, we will be enabled to recognise that conversations are taking place here.

Bloggers A, B and C - with individual differences - exhibit a good, often very good level of appreciation from the internauts. The quantitative indicator chosen for this appraisal is the ratio comments/posts, in all topics and on a yearly basis (first twelve months of life for blogs A and B; extrapolated year for blog C). A detailed analysis was conducted for getting figures of readers' comments per subject, per blog, calculate the corresponding percentages and then rank the latter. This indicator - position in rankings -, although not sophisticated, seems to be a clear proxy for appraising readers' liking of the topics chosen by Bloggers A, B and C as subjects for their posts. 1192 comments were processed for blog A, 113 for blog B and as many as 1039 for the first three months of blog $\mathrm{C}$ (peaks occur in response to posts related to controversies).

Table 4 below depicts the results, with rankings in topics as well as in comments per topic, per blog.

Table 4

Comparison of rankings ${ }^{a}$ by topic choice and by comments, per blog (blogs $A, B, C$; first year)

\begin{tabular}{lcclcclcc}
\multicolumn{2}{c}{ Blog A } & \multicolumn{3}{c}{ Blog B } & \multicolumn{3}{c}{ Blog C } \\
\hline & $\begin{array}{l}\text { Topic } \\
\text { ranking }\end{array}$ & $\begin{array}{c}\text { Comm.s } \\
\text { ranking }\end{array}$ & & $\begin{array}{l}\text { Topic } \\
\text { ranking }\end{array}$ & $\begin{array}{c}\text { Comm.s } \\
\text { ranking }\end{array}$ & \multicolumn{2}{c}{$\begin{array}{c}\text { Topic } \\
\text { ranking }\end{array}$} & $\begin{array}{l}\text { Comm.s } \\
\text { ranking }\end{array}$ \\
\hline SciPure & 3 & 1 & SciPure & 6 & 6 & SciPure & $4 *$ & 2 \\
SciPolitics & 6 & $\mathbf{2}$ & SciPolitics & 4 & 3 & SciPolitics & 5 & $\mathbf{1}$ \\
Personal & 5 & 5 & Personal & 5 & 5 & Personal & $4 *$ & 5 \\
Cult/Soc/Pol & 1 & $\mathbf{6}$ & Cult/Soc/Pol & 2 & 1 & Cult/Soc/Pol & 1 & 3 \\
Acad. Life & 4 & 4 & Acad.Life & 3 & 2 & Acad.Life & 2 & $\mathbf{6}$ \\
Other & 2 & 3 & Other & 1 & $\mathbf{4}$ & Other & 3 & 4 \\
\hline
\end{tabular}

${ }^{\mathrm{a}} 1$ is highest. Ranking gaps $=>3$ are in black; $=2$ are in italics. $*$ Tied for fourth. 
Perceivable mismatches are observable between the relevance attributed to topics - as weighted by rankings - in bloggers' writing on one side and in readers' appreciation, as attested by comments, on the other side. This phenomenon occurs in all three blogs. We consider to be mismatches the gaps of $=>3$ positions in the ranking of a topic on one side, and of the corresponding comments ranking on the other side; and in this case also gaps $=2$, because the underlying percentages in comments for each blog and subject (not detailed presently) are above the average in all three blogs, thus amplyfying the mere ranking gap. These mismatches become key to our understanding of the identity negotiation process which is ongoing behind the conversational exchange between bloggers and their readers.

As shown in Table 4, mismatches occur in Pure Science both in blog A and in blog C (25\% of mismatches), as well as in Science Politics (again, blog A and blog C; further $25 \%$ of mismatches); the only other constant is in Culture/Society/Politics (blogs A and C, further 25\% of mismatches). Both in the case of Pure Science and in that of Science Politics, the differences are ascending, showing the topics concerned seem to be more important for readers than they are for bloggers; the contrary happens for cultural/social topics.

We can add a further and more fine-grained account of this phenomenon for the first year by ranking the posts that have remained uncommented in blogs A and B, by topics (globally: 89 posts). Culture/Society/Politics posts rank first for blog A (35.08\%), while Pure Science and Science Politics posts rank last (7.01\% for both). Posts labelled as "Other" rank first for blog B (40.62\%), while Science Politics ranks last (9.37\%, dead heat with personal posts).

Bloggers' replies to readers' comments, and relative alignment-or-not to appreciation from audience, complete the picture of the dynamics intervening between bloggers and their readers on a subject basis. A total number of 863 replies was processed and the number of replies that each blogger had given to comments in each subject area was calculated (first year), after which a ranking for each subject and blogger was produced (Table 5 below). Table 5 thus integrates the picture given in Table 4.

\section{Table 5}

Complete overview of rankings ${ }^{a}$ in topic choice, comments and replies (blogs A, B, C; first year) 


\begin{tabular}{|c|c|c|c|c|c|c|c|c|c|c|c|}
\hline \multicolumn{4}{|c|}{ Blog A } & \multicolumn{4}{|c|}{ Blog B } & \multicolumn{4}{|c|}{$\mathrm{B} \log \mathrm{C}$} \\
\hline & T. & C. & $\mathrm{R}$. & & $\mathrm{T}$. & C. & R. & & & C. & $\mathrm{R}$. \\
\hline & r. & r. & r. & & r. & r. & r. & & r. & r. & r. \\
\hline SciPure & 3 & 1 & 6 & SciPure & 6 & 6 & 6 & SciPure & 4 & 2 & 6 \\
\hline SciPolitics & 6 & 2 & 2 & SciPolitics & 4 & 3 & 3 & SciPolitics & 5 & 1 & 1 \\
\hline Personal / bio & 5 & 5 & 3 & Personal / bio & 5 & 5 & 2 & Personal / bio & 4 & 5 & 3 \\
\hline Cult./Soc/Pol. & 1 & 6 & 1 & Cult./Soc/Pol. & 2 & 1 & 1 & Cult./Soc/Pol. & 1 & 3 & 5 \\
\hline Acad. Life & 4 & 4 & 5 & Acad. Life & 3 & 2 & 4 & Acad. Life & 2 & 6 & 2 \\
\hline Other & 2 & 3 & 4 & Other & 1 & 4 & 5 & Other & 3 & 4 & 4 \\
\hline
\end{tabular}

${ }^{\mathrm{a}} 1$ is highest. Mismatches $=>3$ are in black; $=2$ are in italics.

T.r. $=$ Topic ranking; C.r. $=$ Comments ranking; R.r. $=$ Replies ranking

Table 5 flags five cases of major mismatch (=>3 ranking positions) between rankings of replies and rankings of comments. Only two of these mismatches occur in the same topic that, remarkably, is again Pure Science, both in blog A and in blog C. All the other cases are irrelated by subject.

\section{Results and discussion}

In an effort to give insight into the overall picture, we propose the following interpretation scheme, which can account for almost all of the major features emerging from Table 5.

There are topics for which the examined bloggers adapt their response to their readers' liking, as measured by yearly quantity of comments per topic (ranking), and other subjects for which they don't. In the second case, they either show a high commitment to replying to a moderate amount of comments, or conversely seem to under-react to a relatively high quantity of comments. In case bloggers' response (replies) is much higher than readers' interest as attested by comments ranking, bloggers are patently showing their continuing interest for the subject notwithstanding readers' tepid reactions. The contrary happens when they appear to under-react to signs of sizeable appreciation from readers.

For Blogger A, non-adaptation to readers' response occurs for cultural/social subjects. Although apparently less appreciated by their readers (last in ranking position by comments), Blogger A keeps their activity on this subject as intense as they had defined it with topic choice, i.e. in first position. Their behaviour is not adaptive with regard to this topic, independently from the 
context's response. Similarly, Blogger $\mathrm{C}$ is not adaptive with regard to Academic Life topics. Although last as for readers' comments, accounts of professional conferences and related social activities keep their second place in this blogger's ranking of replies, the same it had in topic choice ranking. Likewise, in the first year of their blog's life Blogger B doesn't follow their readers' above-average amount of comments for Science Politics (second in comments ranking), downsizing their reply to a 4 th position, the same it had had in topic choice ranking.

The three bloggers' behaviour in the Pure Science area is central to our main research question (RQ4 above). Both Blogger $\mathrm{A}$ and Blogger $\mathrm{C}$ seem not to follow their readers' high feedback to pure science (1st and 2nd respectively in comments ranking), to which they hadn't devoted ample room in their blogs (3rd and 4th position, respectively): both Blogger A and Blogger $\mathrm{C}$ dedicate to this subject their lowest number of replies (6th in ranking of replies, for both). As for Blogger B, we can speculate that they didn't need to somehow counter-balance their readers' liking for pure science, which they had chosen the least among their subjects (6th position), because their audience had already shown a low level of interest for this topic (last in comments ranking).

It appears clearly that these astrophysicists' blogging behaviour exhibits distancing from their professional role's main content, pure science, in multiple ways. Astrophysics is never the first topic of choice; even when it gets a good amount of comments, the after-comment interaction replies - is kept limitate as for amount. In other words, bloggers patently practice a special kind of shift in conversations with their audience, supposedly aimed at steering conversations on different subjects. Considering that the professional conversation among scientists reserves a relevant - if not necessarily primary - role to scientific topics, this appears to be a paramount feature for stating that negotiations are taking place on these bloggers' online identities.

More light on these dynamics is shed by the specific behaviour of bloggers towards their peers (blogs $\mathrm{A}$ and $\mathrm{B}$, first year). This analysis has been made possible by a previous - and demanding - enquiry of all commenters' professions on the basis of data that are publicly available on the internet.

The coding of commenters' professions has resulted to be possible for the comparable percentages of $66.66 \%$ of commenters for blog A and $60.79 \%$ of commenters for blog B (203 commenters altogether). Also, the range of professions is comparable to a good extent. The details won't be provided out of privacy concerns. 
Fellow astrophysicists and other people active on the same subject have been coded under the comprehensive label of "Astro*", which is basically composed by a vast majority of researchers plus $\mathrm{PhD}$ students, postdocs, postgraduate students and a small amount of amateurs. In blog A, the Astro* component accounts for $22.09 \%$ of the total commenters, although a further, very active $1.16 \%$ of multidisciplinary experts could be added. In blog B the Astro* commenters represent $21.56 \%$ of the total commenters.

The astro* component exhibits different commenting behaviours in the two blogs, which might partly be due to one of these bloggers' institutional role during the years considered. Peers of Blogger B comment firstly about Science Politics (40.00\%), then about cultural/social/political subjects (28.00\%; they're often societal issues) and about Academic Life (24.00\%). The "astro*" audience of blog A prefers Pure Science (22.33\%), then Other (19.93\%), Science Politics (18.21\%) and Academic Life (18.21\%).

The attitudes bloggers A and B exhibit towards their Astro* commenters look different. Blogger A seems to to value their peers' comments very much; for example, the Astro* component receives the highest rate of reply per comment (52.57\%). Blogger B seems to be particularly open to experimenting interactions with different professional categories: their most replied category results to be that of mathematicians+chemists $(75 \%)$, followed by "other professions" and by physicists, with the Astro* component ranking only sixth out of eight. These different behaviours reveal that significant features of contexts may be blogger-dependent. Now, though, and very important to our main research goal, in both cases bloggers recoil from "conversing" about pure science with their astro* audience. In blog A, the Astro* readers receive by far and large the majority of their replies when commenting about culture/society/politics $(77.77 \%$ of replies to the comments by the astro* readers; followed by Science Politics, 62.26\%, and Other, 58.62\%) - which ranked only penultimate by percentage of comments from peers. Here too, a tension is evident with regard to this topic. In blog B, the author's peers get most of replies when commenting, again, about cultural/societal/political issues $(57.14 \%$ of replies to astro* comments), followed by Science Politics (37.50\%) and Academic Life (16.66\%).

If benchmarked with these further data, the overall response of these bloggers to their global audience, as illustrated in Table 5, appears in full light. These bloggers' appreciation of their peers' contribution doesn't diminish their will to express themselves independently from the scientific topics that result to be best-liked by colleagues - i.e. Pure Science for Bloggers A and C. The 
conversational strain noted above is confirmed and still insists on the subject area of science, notably on Pure Science that is at the core of astrophysicists' professional relationships. The bloggers in this sample emphasize the cultural/social component of their conversations with their audience; they prefer to talk about music, societal issues, hobbies, literature, personal memories and to this aim they seem to steer the subjects of the overall conversation in their blog to a perceivable extent. All of them exhibit an adaptive behaviour to readers' liking with regard to Science Politics (see Table 5 above), but clearly reserve room for pure science to different conversational settings.

Another common trait to the three bloggers seems to be the appreciation for readers' comments to their biographic posts (see Table 5). None of the bloggers dedicates ample room to this topic (5th position by quantity for bloggers A and B, 4th for Blogger C), and readers' comments look as discreet (5th position in all cases), but when it comes to replying, all the bloggers in the sample give commenters of personal posts a high feedback (3rd, 2nd, 3rd position in rankings, respectively), seeming to show that readers' attention, and sometimes support, is wellappreciated when this subject is concerned.

\section{Conclusions}

It has been correctly pointed out that "[blog] practices are tightly knit to the particlar group where the communication takes place" (Kjellberg, 2014, p.43).

Now, the major literature about communication practices in astrophysics and physics has contended that conversation is a disciplinary-central practice both in the making of science, and in the management of careers through interaction with peers (Crane, 1972; Traweek, 1988; Becher \& Trowler, 2001). Both activities are strictly related to the classic concept of "invisible college" (Crane, 1972), that can be deployed also on subjects other than science (Traweek overtly includes professional "gossip" - p.122 - which, strictly speaking, is almost absent in our sample). As noticed by Zuccala (2006), an invisible college can be perfectly in place also in virtual environments.

On the basis of our analysis, there seems to be little doubt that these astrophysicists' blogs can serve as conversational venues, whose function results to be substantially twofold: a) providing supplementary self-representations of their authors, where - with individual differences - "pure" scientists' profiles are complemented by a varied spectrum of interests, and sometimes expression modes (which haven't been accounted for in the present study but do exist). These integrate, thus modifying, their scholarly personas as professionally known and shape the images of more multifaceted personalities. B) Again with individual differences, these blogs enlarge and diversify 
the authors' ordinary professional audiences, and empower them through conversation, thus establishing additional sets of correspondents whose function can be one of emotional vent or support, with a potential for some amount of professional inspiration (DeMoor \& Efimova, 2004). Function b) may have implications on the respective, strictly-intended invisible colleges, as had rightly been realized by Halavais (2005) and Kjellberg (2014, p.68); arguably, on its same notion.

It seems doubtless that Foucault's theory can provide powerful reading keys for some of these core motivations - although a key question such as whether the author self-modelling practices are at play in the mere realm of self-depiction or have more substantial outcomes seems an extremely difficult one to answer - nor we would ever try to give any kind of temptative answer about our sample. Anyway, the present study analyzes topic choice and subsequent interaction as performed by bloggers and readers, thus focusing on semantics and on the function Jacobson defines as "referential". As such, it seems it can call out also the contribution of a theory that seems to have been little considered in the literature examined, except - to the best of our knowledge - for a mention in Rettberg (Rettberg, 2008, p.3). The reference is to Philippe Lejeune's theory of the autobiographical writing as expressed since "Le pacte autobiographique" (Lejeune, 1996), and then overtly transposed to special kinds of online writing and to blogs (Lejeune, 2000). As summarized a few years later (Lejeune, 2006), the key statements are two: a) the claim for truth - the object of any scientific investigation - has a primary role in the autobiographic writing:

Le pacte autobiographique s'oppose au pacte de fiction. [...] L'autobiographe, lui, vous promet que ce que qu'il va vous dire est vrai [...] Il se comporte comme un historien ou un journaliste, avec la différence que le sujet sur lequel il promet de donner une information vraie, c'est lui-même.

('The autobiographical pact is opposed to the fictional pact. The autobiographer promises you that what he is going to tell you is true [...] He behaves like a historian or a journalist, with the difference that the subject about which he promises to give truthful information is himself.').

and, b), the pursuit of a different public, composed of people outside the ordinary circle, is a typical feature ("Tout repose sur l'opposition de deux publics : les proches, dont on se cache, les autres, dont on quête la reconnaissance" - 'Everything rests upon the opposition of two audiences: the nearby one, from which concealment is sought after, and the other people, whose gratitude is searched for.' Ibid.). 
In the end, we can fruitfully follow Kirkup who has maintained that "blogging as an activity is not only about creating scholarly products, it is 'performative writing' (Gregg 2006). It creates identity through the production of what Giddens (1994) describes as a narrative about the self, but it also does this by providing an alternative medium through which to do it" (2010, p.76). Following this path furtherly (as in Cover, 2012, who examines different social networks) would lead to the manifold and somehow unsettling questions posed by this hermeneutical perspective (Culler, 2011), not excluding, ultimately, queries about the process of science development. This is clearly outside the scope of the present paper. Anyway, it is clear that the blogging activity, also in the disciplinary field of astrophysics, provides fruitful research opportunities in order both to elucidate blogs' internal functioning and to cross-check it against multiple communication theories.

The present research was based on a limited number of blogs. The findings would be strengthened by expanding the research to include a larger number of items of the same kind.

\section{References}

Becher, T., \& Trowler, P. (2001). Academic Tribes And Territories: Intellectual Enquiry and the Culture of Disciplines (2.ed.). The Society for Research into Higher Education and Open University Press.

Blood, R. (2002). The Weblog Handbook: practical advice on creating and maintaining your blog. Cambridge (MA): Perseus.

British Psychological Society. (2017). Ethics Guidelines for Internet-mediated Research. https://www.bps.org.uk/news-and-policy/ethics-guidelines-internet-mediated-research-2017

Bruns, A., \& Jacobs, J. (2006). Introduction. In A. Bruns \& J. Jacobs (Eds.), Uses of blogs (pp. 18). Lang.

Cerulo, K. A. (1997). Identity Construction: New Issues, New Directions. Annual Review of Sociology, 10(23), 385-409.

Cover, R. (2012). Performing and undoing identity online: social networking, identity theories and the incompatibility of online profiles and friendship regimes. Convergence: The International 
Journal of Research into New Media Technologies, 18(2), 177-193. https://doi.org/https://doi.org/10.1177/1354856511433684

Crane, D. (1972). Invisible colleges: diffusion of knowledge in scientific communities. University of Chicago Press.

Culler, J. (2011). Performative language. In Literary Theory: A Very Short Introduction (2.ed., pp. 95-102). Oxford University Press. https://doi.org/10.1093/actrade/9780199691340.001.0001

De Moor, A., \& Efimova, L. (2004). An Argumentation Analysis of Weblog Conversations. In Proceedings of the 9th International Working Conference on the Language-Action Perspective on Communication Modelling (LAP 2004) (pp. 197-212). https://www.tlu.ee/ kpata/haridustehnoloogiaTLU/Moor_Efimova.pdf

Efimova, L., \& De Moor, A. (2005). Beyond personal webpublishing: an exploratory study of conversational blogging practices. In Proceedings of the 38th Hawaii International Conference on System Sciences (107a-107a). Big Island, HI, USA. https://doi.org/10.1109/HICSS.2005.118

Efimova, L., \& Hendrick, S. (2005). In search for a virtual settlement: an exploration of weblog community boundaries. In Communities \& Technologies https://www.academia.edu/download/30962393/weblog-community-boundaries.pdf

Efimova, L. (2009). Passion at work: blogging practices of knowledge workers (PhD thesis). (Supervisor(s): Simons, P.R.J.; Hoog, R. de; Faber, Ed.). Novay. https://dspace.library.uu.nl/handle/1874/34110

Ewins, R. (2005). Who are You? Weblogs and Academic Identity. E-Learning and Digital Media, 2(4), 368-377. https://doi.org/10.2304/elea.2005.2.4.368

Halavais, A. (2005). Scholarly blogging: moving toward the visible college. In A. Bruns \& J. Jacobs (Eds.), Uses of blogs (pp. 117-126). Lang.

Herring, S. C., Scheid, L. A., Bonus, S., \& Wright, E. (2004). Bridging the gap: a genre analysis of weblogs. In Proceedings of the 37th Hawai'i International Conference on System Sciences (HICSS-37). https://doi.org/https://doi.org/10.1108/09593840510601513

Herring, S. C., Kouper, I., Paolillo, J. C., Scheidt, L. A., Tyworth, M., Welsh, P., ... Yu, N. (2005a). Conversations in the blogosphere: an analysis "from the bottom up." In Proceedings of 
the Thirty-Eighth Hawai'i International Conference on System Sciences (HICSS-38) (107b107b). IEEE Press. https://doi.org/10.1109/HICSS.2005.167

Herring, S. C., Scheidt, L. A., Wright, E., \& Bonus, S. (2005b). Weblogs as a bridging genre. Information Technology \& People, 18(2), 142-171. Retrieved from https://www.emerald.com/insight/content/doi/10.1108/09593840510601513/full/html

Herring, S. C. (2010a). Web Content Analysis: Expanding the Paradigm. In J. Hunsinger, M. Allen, \& L. Klastrup (Eds.), The International Handbook of Internet Research (pp. 233-249). Springer. https://doi.org/https://doi.org/10.1007/978-1-4020-9789-8_14

Herring, S. C. (2010b). Computer-Mediated Conversation: Introduction and Overview. Language@Internet, 7, article 2. https://www.languageatinternet.org/articles/2010/2801

Kirkup, G. (2010). Academic blogging: academic practice and academic identity. London Review of Education, 8(1), 75-84.

Kjellberg, S. (2009). Blogs as interfaces between several worlds. A case study of the Swedish academic blogosphere. Human IT, 10(3), 1-45. https://humanit.hb.se/article/view/81/0

Kjellberg, S. (2014). Researchers' blogging practices in two epistemic cultures: the scholarly blog as a situated genre. Human IT, 12(3), 36-77. https://humanit.hb.se/article/view/474

Lejeune, P. (1996). Le pacte autobiographique (2.ed.). Seuil.

Lejeune, P. (2000). «Cher écran... » Journal personnel, ordinateur, Internet. Seuil.

Lejeune, P. (2006). Qu'est-ce que le pacte autobiographique? http://www.autopacte.org/pacte_autobiographique.html

Mahrt, M., \& Puschmann, C. (2014). Science blogging: An exploratory study of motives, styles, and audience reactions. Journal of Science Communication, 13(3), A05. https://jcom.sissa.it/sites/default/files/documents/JCOM_1303_2014_A05.pdf

Mewburn, I., \& Thomson, P. (2017). Towards an academic self? Blogging during the doctorate. In D. Lupton, I. Mewburn, \& P. Thomson (Eds.), The Digital Academic. Critical Perspectives on Digital Technologies in Higher Education. Routledge.

Peterson, E. E. (2011). How conversational are weblogs? Language@internet, 8, article 8. https://www.languageatinternet.org/articles/2011/Peterson 
Puschmann, C. (2013). Blogging. In S. C. Herring, D. Stein, \& T. Virtanen (Eds.), Handbook of pragmatics of computer-mediated communication (pp. 83-108). Mouton.

Rettberg, J. W. (2008). Blogs, Literacies and the Collapse of Private and Public. Leonardo Electronic Almanac, 16(2-3), 1-10. http://jilltxt.net/txt/Blogs--Literacy -and-the-Collapse-ofPrivate-and-Public.pdf

Shema, H., Bar-Ilan, J., \& Thelwall, M. (2012). Research Blogs and the Discussion of Scholarly Information. PLOSone, 7(5), e35869. https://doi.org/10.1371/journal.pone.0035869

Siles, I. (2012). Web Technologies of the Self: The Arising of the "Blogger" Identity. Journal of Computer-Mediated Communication, 17(4), 408-421. https://doi.org/10.1111/j.1083$\underline{6101.2012 .01581 . x}$

Siles, I. (2018). Blogs. In N. Brugger \& I. Milligan (Eds.), The Sage Handbook of Web History (pp. 359-371). Sage.

Traweek, S. (1988). Beamtimes and lifetimes: the world of high energy physicists. Harvard University Press.

Turkle, S. (1994). Constructions and reconstructions of self in virtual reality: playing in the MUD. Mind Culture and Activity, 1(3), 158-167.

Turkle, S. (1999). Cyberspace and Identity. Contemporary Sociology, 28(6), 643-648.

Yus, F. (2011). Cyberpragmatics. Internet-mediated communication in context. Benjamins.

Zuccala, A. (2006). Modeling the invisible college. JASIST, 57(2), 152-168. 